\title{
Assessment of homograft replacement of mitral valve by chest radiographs
}

\author{
C. Salzmann, ${ }^{1}$ G. C. Sutton, K. Chatterjee, I. H. Kerr, and G. A. H. Miller \\ From the Cardiac Department, Brompton Hospital, London
}

The chest radiographs of 26 patients have been analysed before homograft replacement of the mitral valve and at a time (range 2 weeks to 15 months) after operation when measured haemodynamic and angiocardiographic findings were made. In 18 of the patients similar cardiac catheterization data were obtained before operation.

The comparison of pre- and postoperative radiographic appearances of pulmonary veins and left atrium reflected well the state of the homograft valve. Satisfactory homograft function was associated with reduction in upper lobe pulmonary venous dilatation in 86 per cent of the patients and decrease in left atrial size in 81 per cent of the patients, while important homograft regurgitation was associated with no change or increase in pulmonary venous or left atrial dilatation.

Postoperative left ventricular function, assessed by ejection fraction, did not influence these changes in the appearance of the pulmonary veins or the left atrium, nor did it influence alterations in overall heart size.

The chest radiograph is a useful aid in the assessment of mitral valve disease. Not only can valuable information be obtained before operation in patients with mitral valve disease, but comparison of pre- and postoperative radiographs may permit an assessment of the result of various operative procedures including mitral valvotomy, valvuloplasty, and mitral valve replacement (McAfee and Biondetti, 1957; Björk and Malers, 1964; Rastelli, Kincaid, and Kirklin, 1966; Peterson et al., 1967; Gotsman et al., 1967; Milne and Carlsson, 1969). Previous studies of the chest radiograph after mitral valve replacement have been confined to mechanical valves (Björk and Malers, I964; Rastelli et al., I966; Gots-

' man et al., 1967; Peterson et al., I967; Milne and Carlsson, 1969). As well as reflecting the haemodynamic result of replacement of the mitral valve by a mechanical valve, it has been postulated that left ventricular function may be an important determinant of the postoperative chest radiographic appearances - (Judson et al., 1964; Björk and Malers, 1964; Rastelli et al., 1966; Gotsman et al., 1967; Peterson et al., 1967). This study reports the changes in the radiographic appearances in patients before and after mitral valve replace-

Received 8 April 197r.

1 Present address: Division of Cardiology, Department of Internal Medicine, University of Bern, Inselspital, CH-3008 Bern, Switzerland. ment with homograft valves. The radiographic changes have been related to the haemodynamic findings and homograft valve function as determined by postoperative cardiac catheterization. In the majority of patients preoperative catheterization data were also available for comparison. Finally, postoperative left ventricular function has been assessed by measurement of left ventricular volume obtained by a cineangiographic technique (Chatterjee et al., 1971), permitting an analysis of the role of ventricular function in the appearances of the postoperative chest radiograph.

\section{Patients studied}

Twenty-four patients (9 male, is female, age range 15-69 years, mean 48 years) who had isolated homograft replacement of the mitral valve had postoperative investigation by cardiac catheterization. Two of these patients were studied on two occasions, in both instances because of the clinical impression of severe homograft dysfunction on the second occasion. All patients had severe mitral valve disease before operation: 9 had dominant mitral stenosis, 8 dominant mitral regurgitation (4 due to ruptured mitral chordae tendineae), and 7 mixed mitral valve disease. This judgement was based on preoperative clinical and catheterization findings as well as operative findings. Two patients had additional aortic valve disease and 4 patients had moderate tricuspid incompetence. 
Both aortic and pulmonary valve homografts have been used in the replacement valve. The valves have been mounted either on a clothcovered metallic frame (Cleland, Ghadiali, and Lennox, 1972) or in a sleeve of Dacron. The left atrial appendage was never amputated.

\section{Methods of study}

Radiological assessment All patients had routine 6-feet posteroanterior chest radiographs taken at the time of both preoperative investigation and postoperative cardiac catheterization. Assessment of all radiographs was made by three independent observers and in cases of disagreement between the observers the films were reviewed together and an agreed assessment made. All films were analysed with respect to heart size, left atrial size, appearance of the pulmonary veins and pulmonary arteries and septal lines.

a) Heart size was obtained by dividing the maximum width of the cardiac silhouette by the maximum inside width of the thorax and expressed as a percentage (cardiothoracic index). Change in overall heart size was reflected by any change in the cardiothoracic index.

b) Left atrial size was assessed in 5 grades $(0=$ normal, $I=$ slight enlargement, $2=$ moderate enlargement, $3=$ severe enlargement, $4=$ aneurysmal dilatation) according to the criteria of Goodwin et al. (1955).

c) Appearance of upper lobe pulmonary veins was graded $0=$ normal, $I=$ slight enlargement, $2=$ obvious enlargement, and $3=$ considerable enlargement, according to Simon (1958).

d) Appearance of pulmonary arteries was graded according to the criteria of Milne (1963) in 5 grades.

e) Septal lines were noted to be present or absent.

In respect of the size of the left atrium, pulmonary veins, and pulmonary arteries, any change, either increase or decrease, by one or more grades was regarded as a significant change.

Cardiac catheterization data Cardiac catheterization was performed at times varying between 2 weeks and 15 months (average 7 months) after operation. In 18 patients cardiac catheterization and left ventricular cineangiography was also performed before operation. Right and left heart catheterization was performed by standard techniques, all pressure measurements being referred to the midchest level. Mitral valve or homograft valve function was assessed by simultaneous recording of pulmonary artery wedge and left ventricular pressures and by left ventriculography in the right anterior oblique position. The homograft valve was thought to be functioning normally when there was no (grade 0 ) or only trivial (grade I) mitral regurgitation on the left ventricular cineangiogram. Important homograft regurgitation was recognized when there was moderate (grade 2) or severe (grade 3) reflux according to Honey et al. (1969). Any diastolic gradient of 5 or more $\mathrm{mmHg}$ between wedge and left ventricular pressure was considered to indicate significant homograft valve obstruction. A postoperative change in mean pulmonary artery wedge and mean pulmonary artery pressure was regarded as significant when the change in pressure exceeded 5 $\mathrm{mmHg}$.

Left ventricular function was assessed from single plane (anteroposterior) cineangiographic volume analysis with opacification of the left ventricle after injection of contrast medium into the pulmonary artery. The following parameters were derived: end-diastolic volume (EDV), end-systolic volume (ESV), left ventricular stroke volume (LVSV =EDV-ESV), and ejection fraction (EF = LVSV/EDV). All calculations were made using the area-length method of Dodge (Dodge et al., 1966) and by computer as previously described from this hospital (Chatterjee et al., 197I). Normal values for ejection fraction previously reported from this hospital (Chatterjee et al., 197I) are mean $0.70 \pm 0.03$, and left ventricular function in this study was considered to be significantly impaired when the ejection fraction was 0.50 or less. In I patient the ejection fraction could not be assessed.

\section{Results}

Changes in heart size, pulmonary venous dilatation, left atrial size, and appearance of the pulmonary arteries, together with the pertinent haemodynamic findings at cardiac catheterization, are shown in the Table.

No patient had a significant pressure gradient across the homograft valve. There were 2 I patients with normal (grade $O$ or I mitral regurgitation) homograft function and 5 patients with important (grade 2 or 3 mitral regurgitation) homograft regurgitation.

Heart size In the group as a whole there was considerable variation in the change in heart size after operation. Reduction in heart size (I5 patients) occurred only in patients with normally functioning homograft valves. Increasing heart size (4 patients) occurred in 3 of the 5 patients with important homograft regurgitation and in only I patient with a normal homograft valve function. Seven patients had no change in heart size, 2 with important homograft regurgitation and 5 with competent valves.

In those patients with reduction in heart size there was significantly $(P<0.05)$ greater reduction in those whose preoperative lesion was mitral regurgitation or mixed mitral stenosis and regurgitation (mean decrease $9 \cdot 3 \% \pm 4.5 \%$ and $7 \cdot 8 \% \pm 3.5 \%$ respectively) than those with preoperative mitral stenosis (mean decrease $4 \cdot 3 \% \pm \mathrm{I} \cdot 7 \%$ ). Patients showing reduction in heart size invariably had reduction in left atrial size; conversely, in 
TABLE Radiographic, haemodynamic, and angiographic findings after homograft mitral valve replacement

\begin{tabular}{|c|c|c|c|c|c|c|c|c|c|}
\hline $\begin{array}{l}\text { Case } \\
\text { No. }\end{array}$ & $\begin{array}{l}\text { Preop. } \\
\text { lesion }\end{array}$ & $\begin{array}{l}\text { Heart } \\
\text { size }\end{array}$ & $\begin{array}{l}\text { Left } \\
\text { atrial } \\
\text { size }\end{array}$ & $\begin{array}{l}\text { Pulm. } \\
\text { venous } \\
\text { size }\end{array}$ & $\begin{array}{l}\text { Pulm. } \\
\text { art. } \\
\text { size }\end{array}$ & $\begin{array}{l}\text { Mean } \\
\text { pulm. } \\
\text { art. } \\
\text { wedge } \\
\text { pressure }\end{array}$ & $\begin{array}{l}\text { Mean } \\
\text { pulm. } \\
\text { art. } \\
\text { pressure }\end{array}$ & $\begin{array}{l}\text { Ejection } \\
\text { fraction }\end{array}$ & $\begin{array}{l}\text { Homo- } \\
\text { graft } \\
\text { regurgita- } \\
\text { tion }\end{array}$ \\
\hline
\end{tabular}

\begin{tabular}{|c|c|c|c|c|c|c|c|c|c|}
\hline I & MS & $\downarrow$ & $\downarrow$ & $\downarrow$ & $\downarrow$ & $\downarrow$ & $\downarrow$ & $\uparrow$ & $\downarrow$ \\
\hline 2 & MS & $\downarrow$ & $\downarrow$ & $\downarrow$ & $\downarrow$ & $\downarrow$ & $\downarrow$ & $\downarrow$ & $\downarrow$ \\
\hline 3 & MR & $\downarrow$ & $\downarrow$ & $\downarrow$ & $\downarrow$ & $\downarrow$ & $\downarrow$ & $\uparrow$ & $\downarrow$ \\
\hline 4 & MR & $\downarrow$ & $\downarrow$ & $\downarrow$ & $\downarrow$ & $\downarrow$ & $\downarrow$ & $\uparrow$ & $\downarrow$ \\
\hline $5^{\star}$ & MSMR & $\downarrow$ & $\downarrow$ & $\downarrow$ & $\downarrow$ & $\downarrow$ & $\downarrow$ & $\downarrow$ & $\downarrow$ \\
\hline 6 & MS & $\downarrow$ & $\downarrow$ & $\downarrow$ & $\downarrow$ & & & $\downarrow$ & $\downarrow$ \\
\hline $7^{\star}$ & MS & $\downarrow$ & $\downarrow$ & $\downarrow$ & $\downarrow$ & & & $\downarrow$ & $\downarrow$ \\
\hline IO & MSMR & $\downarrow$ & $\downarrow$ & $\downarrow$ & - & & & $\uparrow$ & $\downarrow$ \\
\hline II & MS & $\downarrow$ & $\downarrow$ & $\downarrow$ & - & $\downarrow$ & $\downarrow$ & $\downarrow$ & $\downarrow$ \\
\hline 12 & MSMR & $\downarrow$ & $\downarrow$ & $\downarrow$ & - & $\downarrow$ & $\downarrow$ & $\downarrow$ & $\downarrow$ \\
\hline 13 & MR & $\downarrow$ & $\downarrow$ & $\downarrow$ & - & $\downarrow$ & - & $\downarrow$ & $\downarrow$ \\
\hline I4 & MS & $\downarrow$ & $\downarrow$ & $\downarrow$ & - & - & 一 & $\uparrow$ & $\downarrow$ \\
\hline I9 & MS & - & - & - & - & $\downarrow$ & $\downarrow$ & & $\downarrow$ \\
\hline 20 & MSMR & $\downarrow$ & $\downarrow$ & - & $\downarrow$ & $\downarrow$ & $\downarrow$ & $\uparrow$ & $\downarrow$ \\
\hline 21 & MR & $\uparrow$ & $\uparrow$ & $\uparrow$ & - & $\uparrow$ & - & $\uparrow$ & $\downarrow$ \\
\hline 22 & MS & - & - & - & - & & & $\downarrow$ & $\uparrow$ \\
\hline 23 & MR & - & - & - & - & $\downarrow$ & $\downarrow$ & $\downarrow$ & $\uparrow$ \\
\hline 24 & MR & $\uparrow$ & $\uparrow$ & - & $\uparrow$ & $\uparrow$ & $\uparrow$ & $\downarrow$ & $\uparrow$ \\
\hline $25 t$ & MSMR & $\uparrow$ & $\uparrow$ & $\uparrow$ & $\uparrow$ & $\uparrow$ & $\uparrow$ & $\downarrow$ & $\uparrow$ \\
\hline $26 t$ & MS & $\uparrow$ & $\uparrow$ & $\uparrow$ & $\uparrow$ & $\uparrow$ & $\uparrow$ & $\downarrow$ & $\uparrow$ \\
\hline
\end{tabular}

* First postoperative study.

† Second postoperative study in same patients.

MS Dominant mitral stenosis.

MR Dominant mitral regurgitation.

MSMR Mixed mitral stenosis and regurgitation.

Key: $\downarrow$ Reduction in heart size, left atrial size, upper lobe pulmonary venous dilatation and calibre of pulmonary trunk, main pulmonary artery branches and lobar arteries; reduction in wedge pressure and pulmonary artery pressure; ejection fraction $>0.50$; none or only trivial homograft valve regurgitation.

$\uparrow$ Increase in heart size, left atrial size, pulmonary venous dilatation and pulmonary arterial enlargement; increase in wedge pressure and pulmonary artery pressure; ejection fraction $<0.50$; important homograft valve regurgitation.

- No change in heart size, left atrial size, pulmonary venous dilatation and calibre of pulmonary arteries.

those in whom heart size had increased left atrial size increased. Of 7 patients with unchanging heart size, 5 had unchanged left atrial size and 2 reduction in left atrial size.

There was no relation between the change in heart size and postoperative left ventricular function as judged by ejection fraction. Thus, of 15 patients with reduction in heart size, 8 had impaired left ventricular function (EF $<0.50$ ) (Fig. IA and IB) and 7 had normal left ventricular function (EF $>0.50$ ) (Fig. $2 \mathrm{~A}$ and $B ; 3 A$ and $B$ ). Similarly, unchanging or increasing heart sizes were found in patients with and without impaired left ventricular function.

Pulmonary veins There was a good correlation between changes in upper lobe pul- monary venous dilatation and changes in wedge pressure pre- and postoperatively. Thus, IO of II patients who had pre- and postoperative catheterization and who showed reduction in pulmonary venous dilatation also had reduction in wedge pressure (Fig. $2 \mathrm{~A}$ and B). Seven further patients, who were not studied before operation, also had reduction in pulmonary venous dilatation. Three patients had increase in pulmonary venous dilatation, all with increasing wedge pressures (Fig. 3B $^{\mathrm{B}}$ and $\mathrm{C}$ ). Five patients had no change in pulmonary venous enlargement, of whom 3 had reduction in wedge pressure, I had increase in wedge pressure, and I patient had had no preoperative study.

Homograft valve function was an important determinant of change in pulmonary venous 
dilatation. All patients with reduction in pulmonary venous dilatation had satisfactory homograft valve function. Two of the $3 \mathrm{pa-}$ tients with increase in pulmonary venous enlargement had important homograft regurgitation, while of the 5 patients with no change in pulmonary venous dilatation 3 had important homograft regurgitation and the other 2, with competent homografts, had additional uncorrected aortic valve disease.

Change in pulmonary venous dilatation was not affected by postoperative left ventricular function as judged by the ejection fraction. Thus, of 18 patients with reduction in pulmonary venous dilatation 9 had low ejection fractions (Fig. IA and B) and 9 had normal ejection fractions (Fig. $2 \mathrm{~A}$ and $\mathrm{B}$ ).

Left atrium Similar correlations with respect to change in left atrial size and change in wedge pressure were observed. Thus, Io of II patients who had pre- and postoperative catheterization showed reduction in left atrial size and wedge pressure. Six further patients who were not studied before operation also had reduction in left atrial size. Four patients had an increase in left atrial size, in all of whom wedge pressure had increased. Five patients had no change in left atrial size, 3 of whom had reduction in wedge pressure and 2 had no preoperative study.

All patients with reduction in left atrial size had competent homografts, while 3 of the 4 patients with increase in left atrial size had important homograft regurgitation. Of the 5 patients with no change in left atrial size, 2 had important homograft regurgitation.

Change in left atrial size was not influenced by postoperative left ventricular function. Of the 17 patients with reduction in left atrial size 8 had normal ejection fractions and 9 had reduced ejection fractions.

Septal lines There were 5 patients who had septal lines before with a mean wedge pressure ranging from $30-37 \mathrm{mmHg}, 2$ of whom had dominant mitral stenosis and 3 mixed mitral valve lesions. No patient had septal lines after operation, even though there were 5 patients with important homograft valve regurgitation and mean wedge pressures between 30 and $36 \mathrm{mmHg}$.

Pulmonary arteries Fourteen patients had reduction in size of the pulmonary trunk, main pulmonary artery branches, and lobar arteries. Eight of these 14 patients had measured reduction in pulmonary artery pressure and 6 had had no preoperative study. Three patients had increase in size of the pulmonary arteries, all of whom had measured increase

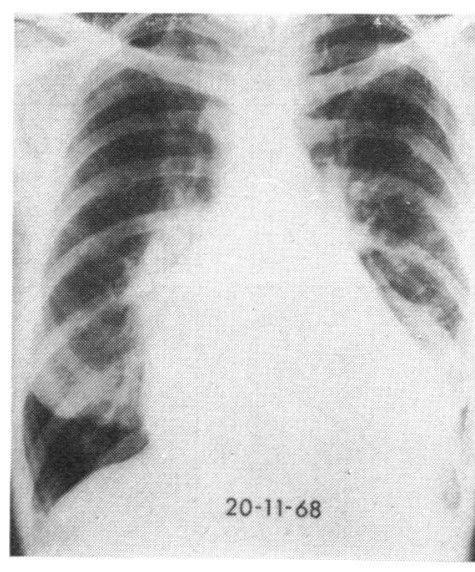

A

FIG. I Case 8. Dominant mitral regurgitation. $(A)$ The preoperative radiograph shows a large heart with large left atrium and obvious upper lobe pulmonary venous dilatation. (B) The postoperative radiograph shows reduction in heart size with reduction in left atrial size and considerable decrease in upper lobe pulmonary venous dilatation. Postoperative cardiac catheterization revealed satisfactory homograft valve function but impaired left ventricular function (ejection fraction <0.50).

in pulmonary artery pressure. Nine patients had no change in size of the pulmonary arteries, of whom 4 had reduction in pulmonary artery pressure, 3 no change, and 2 patients had no preoperative study.

All patients with reduction in size of the pulmonary arteries had competent homograft valves. All 3 patients with increase in size of the pulmonary arteries had important homograft regurgitation. Of the 9 patients with no change in size of the pulmonary arteries, 2 had important homograft regurgitation.

Change in size of the pulmonary arteries was not affected by postoperative left ventricular function as judged by the ejection fraction. Of the 14 patients with reduction in size of the pulmonary arteries, 8 had low ejection fractions and 6 had a normal ejection fraction.

\section{Discussion}

This study shows that comparison of preand postoperative chest radiographs is a simple and reliable method of providing im- 
portant information about the result of homograft replacement of the mitral valve. In judging the operative result the single most useful radiographic sign was the alteration in upper lobe pulmonary venous dilatation which correlated well with the measured reduction in pulmonary artery wedge pressure. Of 21 patients with satisfactory homograft valve function, 18 had reduction in upper lobe venous dilatation which could occur as early as 2 weeks after operation.

Such frequent reduction in upper lobe pulmonary venous enlargement in this series of patients with mitral valve replacement by homograft valves contrasts with much less frequent reversion in reported series of patients after mitral valve replacement by mechanical valves (Rastelli et al., 1966; Gotsman et al., 1967; Milne and Carlsson, 1969) or after closed mitral valvotomy (Goodwin et al., 1955; McAfee and Biondetti, 1957; Milne and Carlsson, 1969). This important difference may be explained by the non-obstructive properties of the homograft valve (Gianelly et al., 1968; Angell et al., 1969) by comparison with mechanical valves (Morrow et al., 1964; Judson et al., 1964; Beck et al., 1965), or by residual stenosis after closed mitral valvotomy (Donald et al., 1957; Braunwald et al., 1965; Milne and Carlsson, 1969; Higgs et al., 1970). Reduction in left atrial size similar to reduction in pulmonary venous dilatation occurred
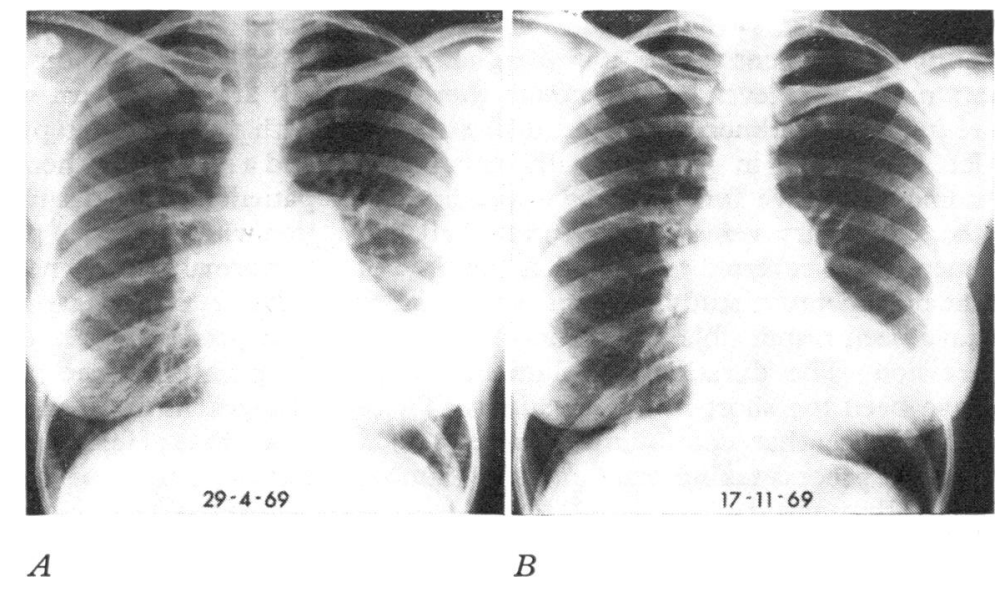

FIG. 2 Case 2. Dominant mitral stenosis. (A) The preoperative radiograph shows a large pulmonary trunk, obvious upper lobe venous dilatation, and septal lines. Mean wedge pressure $37 \mathrm{mmHg}$; mean pulmonary artery pressure $68 \mathrm{mmHg}$. (B) The postoperative film shows decrease in heart size and size of the pulmonary trunk. The upper lobe pulmonary veins are now almost normal. The septal lines have disappeared. Postoperative cardiac catheterization showed satisfactory homograft valve function and normal left ventricular function (ejection fraction $>0.50$ ). Wedge and pulmonary artery pressure now normal.

FIG. 3 Case 5. Mixed mitral stenosis and regurgitation. $(A)$ The preoperative film shows obvious dilatation of the upper lobe pulmonary veins. Mean wedge pressure $33 \mathrm{mmHg}$; mean pulmonary artery pressure $50 \mathrm{mmHg}$. (B) The postoperative radiograph shows reduction in heart size and considerable reduction in upper lobe pulmonary venous dilatation. Satisfactory homograft valve function and normal left ventricular function (ejection fraction $>0.50$ ) were shown by postoperative cardiac catheterization. Mean wedge pressure $16 \mathrm{mmHg}$; mean pulmonary artery pressure $21 \mathrm{mmHg}$. (C) Three months later the radiograph shows increase in heart size and marked dilatation of the upper lobe pulmonary veins. A further cardiac catheterization now showed severe homograft valve regurgitation. Left ventricular function was unchanged (ejection fraction $>0.50$ ).

$A$

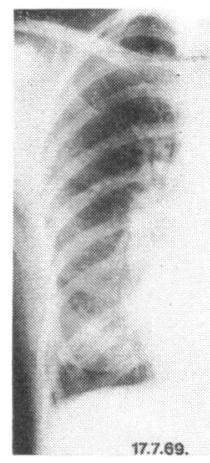

$B$

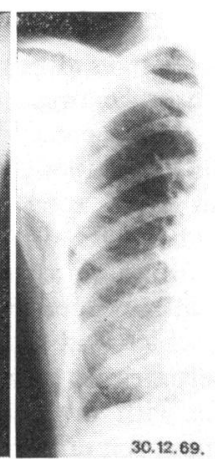

C

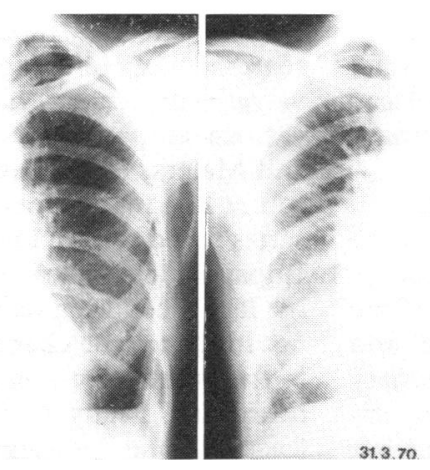

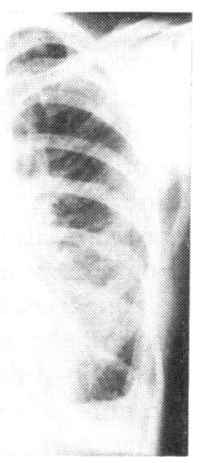


in those patients who had satisfactory homograft replacement of the mitral valve ( 17 of 2 I patients). Nevertheless, though there was reduction in pulmonary venous dilatation and left atrial size in patients with satisfactory homograft valve function, the appearance of the pulmonary veins or left atrium had frequently not reverted to normal at the time of the postoperative study. Various factors might have been responsible for this incomplete regression. The duration of follow-up might have been too short in some patients. There is evidence that continuing regression is a gradual process taking many months (Simon, 1958; Braunwald et al., 1965). Many patients had residual slight increase in wedge pressure due to postoperative rise in left ventricular end-diastolic pressure (e.g. due to additional aortic valve disease) which might contribute to nonregression to normal (Rockoff et al., 1966; Peterson et al., 1967; Hultgren, Hubis, and Shumway, I968). Residual dilatation of the left atrium may be due to continuing atrial fibrillation (Fleming and Wood, 1959; Chen et al., 1968), and in this series the 5 patients with normal left atrial size after operation were all in sinus rhythm. Another factor responsible for residual left atrial dilatation may be the loss of elasticity after prolonged duration of mitral valve disease (Melhem, Dunbar, and Booth, 196I; Gotsman et al., 1967; Chen et al., 1968). Permanent dilatation of the pulmonary veins due to loss of elasticity is thought to occur to a lesser extent (Milne and Carlsson, 1969). Just as reduction in pulmonary venous and left atrial size was a prominent feature in patients with a satisfactory homograft result, an increase in size indicated important homograft regurgitation. The importance of this feature was emphasized by 2 patients whose homograft was initially satisfactory and who later developed severe regurgitation. Both these patients showed striking deterioration in the radiographs, with increase in pulmonary venous and left atrial dilatation, corresponding with measured haemodynamic and angiocardiographic deterioration (Fig. 3A, B, and C). Such changing radiographic appearances have been seen in 2 other patients whose homograft had to be replaced for severe regurgitation but who did not have further cardiac catheterization.

In common with Milne and Carlsson (1969), we have found it more difficult to make a satisfactory assessment of the pulmonary arterial pattern than of the appearance of the pulmonary veins. Comparison of the pre- and postoperative appearances of the pulmonary arteries was less useful than similar comparison of pulmonary venous enlargement or left atrial size in assessing the operative result. Though obvious improvement in the pulmonary arterial pattern was invariably associated with a reduction in pulmonary artery pressure and a satisfactory homograft result, there were patients who had satisfactory homograft function with a return of pulmonary artery pressure to normal and yet had no change in the conspicuous pulmonary hypertensive arterial pattern present before operation. Such findings suggest that some patients have irreversible changes in their pulmonary arteries (Doyle et al., 1957; Heath and Edwards, 1959), giving rise to abnormal radiographic appearances unaffected by obvious reductions in pulmonary artery pressure (Fig. 2A and B).

Changes in heart size were closely paralleled by changes in left atrial size in the same patients and reflected the state of the homograft valve to a certain extent. Nevertheless, in mitral valve replacement by homograft or mechanical valves there are factors other than the state of the replaced mitral valve which may be responsible for alterations in overall heart size after operation (Björk and Malers, I964; Judson et al., 1964; Rastelli et al., 1966; Peterson et al., 1967; Gotsman et al., 1967; Hultgren et al., 1968). For instance, the preoperative mitral valve lesion may be important in determining changes in heart size (Gotsman et al., 1967; Schrire and Barnard, 1970) and, indeed, those patients in this series with satisfactory homograft function had significantly greater reduction in heart size if the preoperative lesion was mitral regurgitation than if it was mitral stenosis. Uncorrected additional valve lesions may also be responsible for lack of improvement in heart size (Braunwald et al., I965; Peterson et al., 1967). Aortic valve disease might result in increase in left ventricular or left atrial size and tricuspid valve disease might result in persisting right heart dilatation. The number of patients with such lesions in this series was too small for meaningful analysis to be made.

The view that postoperative impairment of left ventricular function results in nonregression of radiographic changes after mitral valve replacement has been expressed by various authors (Judson et al., I964; Björk and Malers, 1964; Rastelli et al., 1966; Peterson et al., 1967; Gotsman et al., 1967). This series failed to provide evidence for this view. Impaired left ventricular function, as judged by low ejection fraction after operation did not influence the changes which had occurred in the pulmonary veins, left atrium, or overall heart size. Many patients with low ejection fractions had striking improvement in pul- 
monary venous, left atrial, and heart size provided that homograft function was satisfactory. Conversely, some patients with normal ejection fractions had increase in pulmonary venous dilatation, left atrial size, and overall heart size when severe homograft regurgitation was present. Whether impaired left ventricular function had been present before operation or followed operation was not determined in this series of patients who did not have ejection fractions measured before operation. The role of alterations in left ventricular function in influencing the radiographic changes in these patients consequently could not be assessed. However, the 2 patients studied on two occasions after operation who developed severe homograft regurgitation had unchanging ejection fractions and yet obvious deterioration in pulmonary venous and left atrial dilatation and overall heart size.

We would like to thank Dr. R. V. Gibson and Dr. M. Honey for permission to study the patients under their care.

\section{References}

Angell, W. W., Iben, A. B., Gianelly, R. E., and Shumway, N. E. (1969). Aortic homografts for mitral valve replacement. Circulation, 39, Suppl. I, p. 39.

Beck, W., Fergusson, D. J. G., Barnard, C. N., and Schrire, V. (1965). Hemodynamic findings following replacement of the mitral valve with the University of Cape Town prosthesis. Circulation, 32, 721.

Björk, V. O., and Malers, E. (1964). Total mitral valve replacement: Late result. fournal of Thoracic and Cardiovascular Surgery, 48, 625.

Braunwald, E., Braunwald, N. S., Ross, J., Jr., and Morrow, A. G. (1965). Effects of mitral-valve replacement on the pulmonary vascular dynamics of patients with pulmonary hypertension. New England fournal of Medicine, 273, 509.

Chatterjee, K., Sacoor, M., Sutton, G. C., and Miller, G. A. H. (197I). Assessment of left ventricular function by single plane cineangiographic volume analysis. British Heart fournal, 33, 565.

Chen, J. T. T., Behar, V. S., Morris, J. J., Jr., McIntosh, H. D., and Lester, R. G. (I968). Correlation of roentgen findings with hemodynamic data in pure mitral stenosis. American fournal of Roentgenology, 102, 280.

Cleland, W. P., Ghadiali, P. E., and Lennox, S. C. (1972). Mounted mitral homografts. In Biological Tissue in Heart Valve Replacement, p. 399. Ed. by M. I. Ionescu, D. N. Ross, and G. H. Wooler. Butterworth, London.

Dodge, H. T., Sandler, H., Baxley, W. A., and Hawley, R. R. (1966). Usefulness and limitations of radiographic methods for determining left ventricular volume. American fournal of Cardiology, 18, 10.

Donald, K. W., Bishop, J. M., Wade, O. L., and Wormald, P. N. (1957). Cardio-respiratory function two years after mitral valvotomy. Clinical Science, 16, 325 .
Doyle, A. E., Goodwin, J. F., Harrison, C. V., and Steiner, R. E. (1957). Pulmonary vascular patterns in pulmonary hypertension. British Heart fournal, 19, 353 .

Fleming, H. A., and Wood, P. (1959). The myocardial factor in mitral valve disease. British Heart fournal, 21, 117 .

Gianelly, R. E., Angell, W. W., Stinson, E., Shumway, N. E., and Harrison, D. C. (1968). Homograft replacement of the mitral valve. Circulation, 38, 664.

Goodwin, J. F., Hunter, J. D., Cleland, W. P., Davies, L. G., and Steiner, R. E. (1955). Mitral valve disease and mitral valvotomy. British Medical fournal, 2, 573.

Gotsman, M. S., Beck, W., Barnard, C. N., and Schrire, V. (1967). Changes in the appearances of the chest radiograph after a repair or replacement operation on the mitral valve. British fournal of Radiology, 40, 724.

Heath, D., and Edwards, J. E. (1959). Histological changes in the lung in diseases associated with pulmonary venous hypertension. British fournal of Diseases of the Chest, 53, 8.

Higgs, L. M., Glancy, D. L., O’Brien, K. P., Epstein, S. E., and Morrow, A. G. (1970). Mitral restenosis: an uncommon cause of recurrent symptoms following mitral commissurotomy. American fournal of Cardiology, 26, 34.

Honey, M., Gough, J. H., Katsaros, S., Miller, G. A. H., and Thuraisingham, V. (1969). Left ventricular cine-angiocardiography in the assessment of mitral regurgitation. British Heart fournal, 31, 596.

Hultgren, H., Hubis, H., and Shumway, N. (1968). Cardiac function following mitral valve replacement. American Heart fournal, 75, 302.

Judson, W. E., Ardaiz, J., Strach, T. B. J., and Jennings, R. S. (1964). Postoperative evaluation of prosthetic replacement of aortic and mitral valves. Circulation, 29, Suppl. I, p. I4.

McAfee, J. G., and Biondetti, P. (I957). Roentgenologic follow-up on 150 consecutive mitral commissurotomy patients. American fournal of Roentgenology, 78, 213.

Melhem, R. E., Dunbar, J. D., and Booth, R. W. (I96I). The ' $B$ ' lines of Kerley and left atrial size in mitral valve disease: their correlation with the mean left atrial pressure as measured by left atrial puncture. Radiology, 76, 65 .

Milne, E. N. C. (1963). Physiological interpretation of the plain radiograph in mitral stenosis, including a review of criteria for the radiological estimation of pulmonary arterial and venous pressures. British fournal of Radiology, 36, 902.

Milne, E. N. C., and Carlsson, E. (1969). Physiological interpretation of the plain radiograph following mitral valvotomy, valvuloplasty, and prosthetic replacement. Radiology, 92, 1201.

Morrow, A. G., Clark, W. D., Harrison, D. C., and Braunwald, E. (1964). Prosthetic replacement of the mitral valve. Operative methods and the results of preoperative and postoperative hemodynamic assessments. Circulation, 29, Suppl. I, p. 2.

Peterson, C. R., Herr, R., Crisera, R. V., Starr, A., Bristow, J. D., and Griswold, H. E. (1967). The failure of hemodynamic improvement after valve replacement surgery. Etiology, diagnosis and treatment. Annals of Internal Medicine, 66, $\mathrm{x}$.

Rastelli, G. C., Kincaid, O. W., and Kirklin, J. W. (1966). Heart size after isolated replacement of mitral or aortic valve. Mayo Clinic Proceedings, 4I, 217. 
Rockoff, S. D., Ross, J., Jr., Oldham, N. N., Mason, D. T., Morrow, A. G., and Braunwald, E. (1966). Ventriculo-atrial regurgitation following prosthetic replacement of the mitral valve. Angiocardiographic and hemodynamic findings. American fournal of Cardiology, 17, 817.

Schrire, V., and Barnard, C. N. (1970). Immediate and long-term results of mitral valve replacement with
University of Cape Town mitral valve prosthesis. British Heart fournal, 32, 245.

Simon, M. (1958). The pulmonary veins in mitral stenosis. Fournal of the Faculty of Radiologists, 9, 25.

Requests for reprints to Dr. I. H. Kerr, the Cardiac Department, Brompton Hospital, London S.W.3. 